\title{
Salutogenesis From Its Origins to the Present
}

\author{
Maurice B. Mittelmark
}

Part I provides an overview of the development of the field of salutogenesis, as background for the remaining chapters in The Handbook of Salutogenesis.

Chapter 2 by Bengt Lindström reviews mileposts in the development of the field from the late 1990s until today. This is a chronology of the meetings, seminars and other events that have provided space and time for the development of salutogenesis as an academic field. This chapter is of historical value and helps describe the global collaborative work that has supported the network of colleagues whose work is in the book.

Chapter 3 by Maurice Mittelmark and Georg Bauer is a revision and expansion of a chapter in the 2017 Edition, meant to convey some of the main ways the term 'salutogenesis' is used today. Antonovsky introduced the term salutogenesis in his 1979 and 1987 books on the Salutogenic Model of Health, but salutogenesis subsequently has come to refer to a core concept in the Model in particular; the sense of coherence. This usage has advanced to the point that some writers have coined the term 'sense of coherence theory'. The term salutogenesis is also frequently used to refer, more generally, to an approach to health theory, research and practice emphasising resources that people may call on to improve health.

Chapter 4 is of particular importance in this Handbook. Written by Aaron Antonovsky's son Avishai Antonovsky, and by one of his closest colleagues and former PhD student, Shifra Sagy, this revised chapter from the 2017 Edition provides the first biography of the founding father of salutogenesis. The authors share their insight regarding the development of the salutogenic idea. They were very close to Aaron Antonovsky for several decades, and their familiarity with his background contributes to understanding the development of salutogenesis.

M. B. Mittelmark ( $\square)$

Department of Health Promotion and Development,

Faculty of Psychology, University of Bergen, Bergen, Norway

e-mail: maurice.mittelmark@uib.no
Chapter 5 by Hege Forbech Vinje, Eva Langeland and Torill Bull is reproduced from the 2017 Edition. The editors are convinced that this summary of Antonovsky's development of the Salutogenic Model of Health is among the best synopses available. While no summary can replace the value of Antonovsky's voluminous productivity on salutogenesis, the reader of this chapter will receive a quite in-depth introduction to Salutogenesis's main lines of development under the guiding hands of its founding theoretician.

Chapter 6 by Georg Bauer provides the reader with a useful description of Salutogenesis meeting places. These are the Society for Theory and Research on Salutogenesis (STARS) and the Global Working Group on Salutogenesis (GWG-Sal) of the International Union for Health Promotion and Education (IUHPE). Bauer also provides information about the Center on Salutogenesis at the University of Zürich in Switzerland. The center is the host organisation of both meeting places. The reader wanting to connect more directly to a global salutogenesis network will find this chapter to be of great practical value.

Finally, Chapter 7 by Lenneke Vaandrager of The Netherlands and colleagues from Spain, Germany, Italy, Norway, the United Kingdom and Poland trace the development of higher education in salutogenesis in Europe, spanning 30 years. At this time, the annual summer schools of the European Training Consortium in Public Health and Health Promotion have trained more than 700 participants from 60 countries. Perhaps the most distinguished member of the summer school's faculty - at least from the perspective of advancing salutogenesis as a theory for health promotion - is Aaron Antonovsky, who participated in the 1992 edition of the course in Gothenburg, Sweden.

The chapters of Part I provide the reader with an overview of the entire scope of development of salutogenesis from its start in 1979 to this day. Just over a mere 40 years, a very rapid eye blink in social science history! Therefore, this book is an introduction to a transdisciplinary field in its infancy. The reader is heartily invited to join in on the 'ground-floor' of the research, theory building and prac- 
tice that we anticipate will advance salutogenesis to a mature scholastic undertaking. What is the fundamental problem that makes this audacious undertaking worth the effort?
How may we better understand the origins of human health? How may we advance health in a manner considerate of the connectedness of health to life generally?

Not just human life, but global life.

Open Access This chapter is licensed under the terms of the Creative Commons Attribution 4.0 International License (http://creativecommons. org/licenses/by/4.0/), which permits use, sharing, adaptation, distribution and reproduction in any medium or format, as long as you give appropriate credit to the original author(s) and the source, provide a link to the Creative Commons license and indicate if changes were made.

The images or other third party material in this chapter are included in the chapter's Creative Commons license, unless indicated otherwise in a credit line to the material. If material is not included in the chapter's Creative Commons license and your intended use is not permitted by statutory regulation or exceeds the permitted use, you will need to obtain permission directly from the copyright holder. 